\title{
Modelling and thermography measurements of thermal wake effect in electronic components
}

by M. Felczak and B. Więcek

Technical University of Łódź, Wólczańska 223, 90-924 Lodz, Poland

\begin{abstract}
In this paper, investigations of thermal wake effect are presented. Two flat heat sources placed one after, another cooled with forced laminar convection were considered. Paper includes numerical simulations of these two flat heat sources cooled by forced convection as well. Real model of heat sources has also been investigated in a wind tunnel.
\end{abstract}

\section{Introduction}

Power densities generated in todays electronic components arise very quickly. Electronic components such as VLSI (Very Large Scale Integration) are placed on Printed Circuit Boards (PCB). Optimal placement of the devices on the board plays very important role for dissipation of power to the ambience. Each electronic component, as a heat source, thermally interacts with other ones. Forced convection is still one of the most important ways of heat dissipating from electronic components. When fluid moves along the board, the components placed upstream have better cooling conditions than the ones placed downstream. It happens because moving fluid warms up. This phenomenon is called thermal wake effect.

\section{Numerical simulations}

Three dimensional simulations of two heat sources and the PCB were performed. Fig.1 shows geometry, which was applied for simulations. To simplify the problem these sources were flat. Adiabatic conditions were applied for the external PCB edges. Printed circuit board was assumed to be made with poorly thermally conducting material. Its thermal conductivity was assumed to be equal to $0.25 \frac{\mathrm{W}}{\mathrm{m} \cdot \mathrm{K}}$. Fluid was moving from right to left side with velocities ranging from $2-3 \mathrm{~m} / \mathrm{s}$. Printed circuit boards length is equal to $0.11 \mathrm{~m}$, while its width is $0.09 \mathrm{~m}$. Sources were square $(0.03 \times 0.03 \mathrm{~m})$.

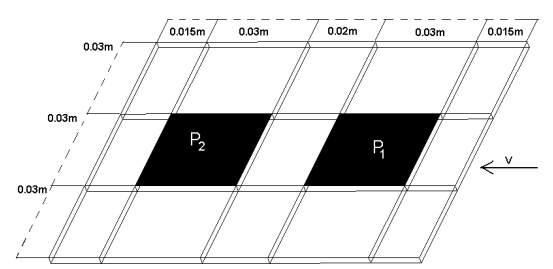

Fig.1. Three dimensional geometry applied for simulations B.7.1 
Distance between sources for all the simulations sets, was the same $(0.02 \mathrm{~m})$. Simulation results were validated with tests completed in a wind tunnel. Simulations and tests were carried out for four different power values generated in heat sources and three different velocit of air. For all simulation sets powers generated in both sources was equal. We wanted to observe if thermal wake effect should really be taken into account for downstream module. The thermal wake function $\theta$ is defined as [2]

$\theta=\frac{T_{2}-T_{a}}{T_{1}-T_{a}}$

where

$T_{a}$ - ambient temperature

$T_{1}$ - temperature of the upstream source

$T_{2}$ - temperature of the downstream source

Heat source placed downstream had higher temperature than the upstream one. Numerical simulations were carried out using Fluent software.

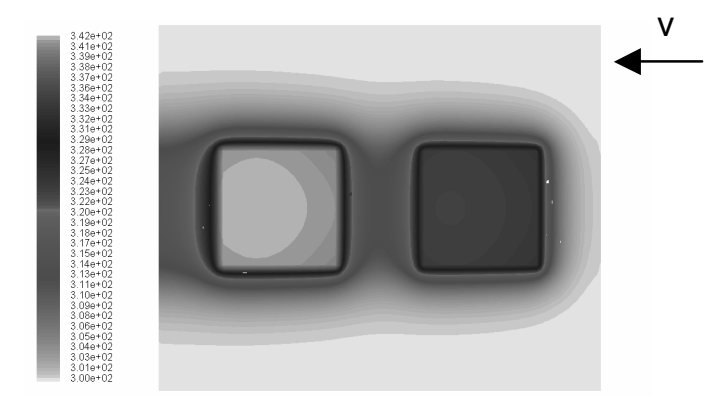

Fig.2. Example of temperature distribution

In Fig.2 distribution of heat sources and PCB temperature is presented. It is visible that source at the left side (downstream one) has higher temperature.

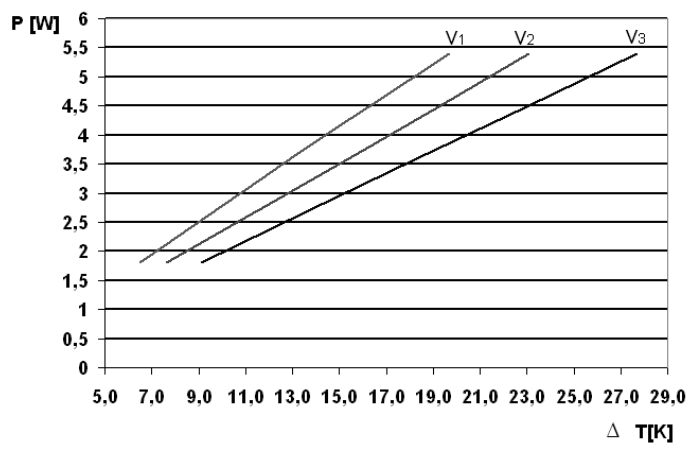

Fig.3. Function of temperature difference between left and right heat source versus power dissipated by each of them for three different velocities $\left(v_{1}, v_{2}, v_{3}\right)$, (simulations). 
This temperature difference is well visible during all measurements. Graph which shows dependency between sources temperature differences $(\Delta T)$ versus dissipated power is presented above (Fig.3).

Simulations were performed for three different velocities $(2.0,2.5,3.0 \mathrm{~m} / \mathrm{s})$. It is visible that dependency between temperature differences and power is linear.

\subsection{Wind tunnel testing}

The experimental setup consists mainly of the low-speed wind tunnel with maximum velocity equal to about $5 \mathrm{~m} / \mathrm{s}$ (Fig.4). Tunnel is equipped with a window for thermographic measurements, which is made of germanium. Germanium is transparent for infrared radiation in range $8-12 \mu \mathrm{m}$, what makes possible to measure temperature distribution on the surface of the plate.

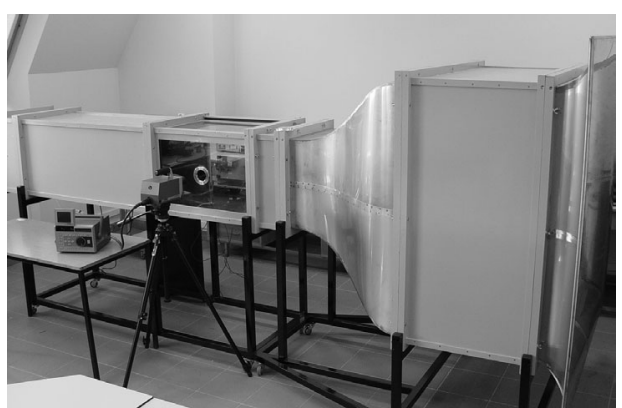

Fig.4. Low speed wind tunnel used for measurements

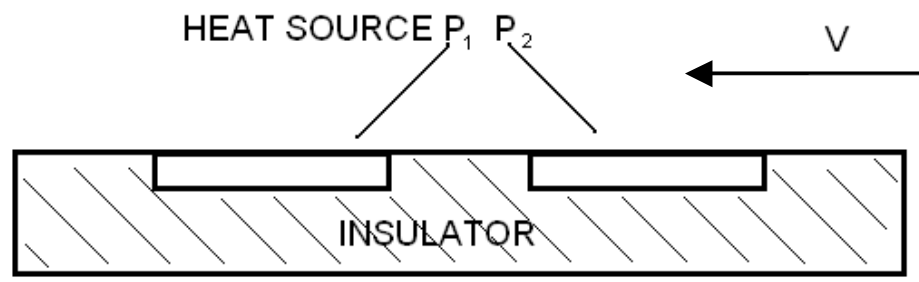

Fig.5. Cross section of plate used for experiments

For investigations the flat plate with two square heat sources was made. Its geometry corresponds to simulated one. All dimensions and distance between sources are the same as applied in simulations. To reduce conduction, this plate was made with insulator. Cross section of the plate is presented in Fig. 5. Heat sources are insulated at the bottom side. It enables to determine power dissipated from the top of them precisely. Each of the modules consists of brass block and 2 resistors $4.7 \Omega$ supplying heat from the bottom. In real electronic systems heat is released also by other phenomenon such as thermal conduction in PCB. Usage of such a module as in Fig. 3 enables investigating thermal wake effect with forced convection as only way of heat dissipating from the heat sources. 
Similarly as for simulations, the power dissipated in both heat sources was equal. This work contains experiments where dissipated power and air velocity vary. Measurements were carried out for four different power quantities dissipated in heat sources and three different velocities.

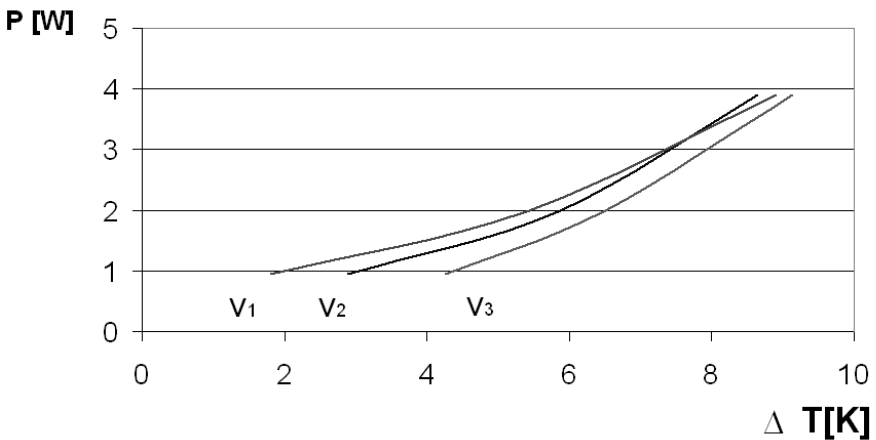

Fig.6. Function of temperature difference between left and right heat source against power dissipated by each of them for three different velocities $\left(v_{1}, v_{2}, v_{3}\right)$.

Dependency $\Delta T=f(P)$ obtained from measurements is presented above (Fig.6). For higher dissipated power the temperature differences seems to be less dependent from air velocity than for small power.

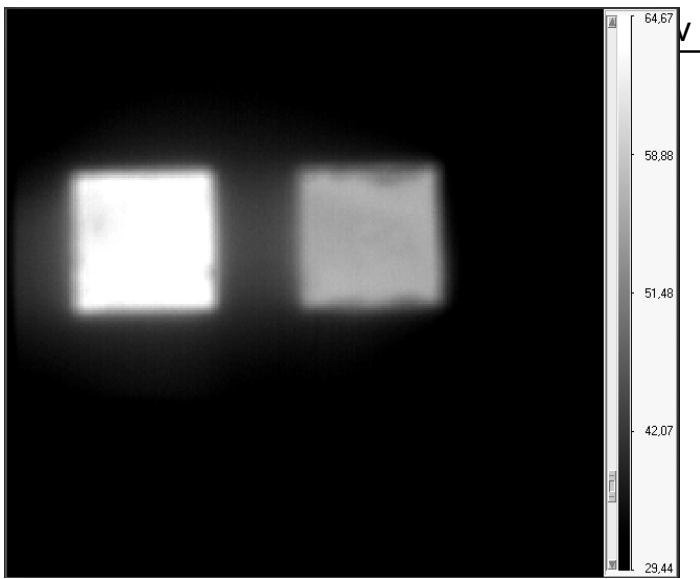

Fig.7. Example of temperature distribution

In Fig.7 example of the thermograms is presented. It is well visible that the left heat source (downstream one) is hotter. 
Table 1. Temperature difference between heat sources and thermal wake function $(\theta)$ obtained from measurements

\begin{tabular}{|l|l|l|l|}
\hline $\mathrm{V}[\mathrm{m} / \mathrm{s}]$ & $\mathrm{P}[\mathrm{W}]$ & $\Delta \mathrm{T}[\mathrm{K}]$ & $\theta$ \\
\hline 2.0 & 1 & 2.8 & 1.6 \\
\hline 2.0 & 2 & 5.8 & 1.4 \\
\hline 2.0 & 3 & 7.6 & 1.4 \\
\hline 2.0 & 4 & 8.6 & 1.3 \\
\hline 2.5 & 1 & 1.8 & 1.6 \\
\hline 2.5 & 2 & 5.3 & 1.5 \\
\hline 2.5 & 3 & 7.7 & 1.4 \\
\hline 2.5 & 4 & 8.9 & 1.3 \\
\hline 3.0 & 1 & 4.2 & 1.9 \\
\hline 3.0 & 2 & 6.4 & 1.7 \\
\hline 3.0 & 3 & 7.9 & 1.4 \\
\hline 3.0 & 4 & 9.1 & 1.3 \\
\hline
\end{tabular}

Thermal wake function takes the highest values for maximum air velocity (Tabele 1). It means that for the best cooling conditions, the highest differences in heat releasing from heat sources occur.

\subsection{Conclusions}

Experiments and simulations confirmed that the thermal wake effect can play important role for electronic systems cooling. Dependency between $\Delta T=f(P)$ differs for simulation and experimental results. There are visible differences of temperature of upstream and downstream source. For simulations it is practically linear function of power. From experiments it results that for high dissipated power velocity changes does not play such a role as for a small. Temperature differences seems to be the same for the whole speed range.

In order to improve cooling conditions, the additional elements can be added on the PCB to change air flow direction[2]. This will be the main subject in the future works.

\section{REFERENCES}

[1] A.K. da Silva, S. Lorente, A. Bejan. Optimal distribution of discrete heat sources on a plate with laminar forced convection, International Journal of Heat and Mass transfer 47 (2004) 2139-2148.

[2] B.A. Jubran, A.S. Al- Salaymech. Thermal wakes measurement in electronic modules in the presence of heat transfer enhancement devices, Applied Thermal Engineering 19 (1999) 1081-1096

[3] Anderson, A.M., 1997, "Comparison of Computational and Experimental Results for Flow and Heat Transfer from an Array of Heated Blocks," Journal of Electronic Packaging, Transactions of the ASME, Vol. 119, pp. 32-39. 
[4] Anderson, A. M., and Moffat, R. J., 1990, "A New Type of Heat Transfer Correlation for Air Cooling of Regular Arrays of Electronic Components," Proceedings of ASME Winter Annual Meeting, pp. 27-39.

[5] Arvizu, D. E., and Moffat, R. J., 1982, "The Use of Superposition in Calculating Cooling Requirements for Circuit Board Mounted Electronic Components," Proceedings of the 32nd Electronic Components Conference, IEEE, Vol. 32, pp. 133-144.

[6] Faghri, M., Ray, A., and Sridhar, S., 1991, "Entrance Heat Transfer Correlation for Air Cooling of Arrays of Rectangular Blocks," Heat Transfer Enhancement in Electronics Cooling, ASME HTD-Vol. 183, pp. 19-23.

[7] Leung, C. W., and Kang, H. J., 1998, "Convective Heat Transfer from Simulated Air-Cooled Printed-Circuit Board Assembly on Horizontal or Vertical Orientation," International Communications in Heat and Mass Transfer, Vol. 25, No. 1, pp. 67-80.

[8] Moffat, R. J., Arvizu, D. E., and Ortega, A., 1985, "Cooling Electronic Components: Forced Convection Experiments with an Air-Cooled Array," Heat Transfer in Electronic Equipment, ASME HTD-Vol. 48, pp. 17-27.

[9] Moffat, R. J., and Anderson, A. M., 1988, "Applying Heat Transfer Coefficient Data to Electronics Cooling," presented at the ASME Winter Annual Meeting, Chicago, IL.

[10] Molki, M., Faghri, M., and Ozbay, O., 1995, " A Correlation for Heat Transfer and Wake Effect in the Entrance Region of an In-Line Array of Rectangular Blocks Simulating Electronic Components," ASME Journal of Heat Transfer, Vol. 117, pp. 40-46. 